\title{
Non-ionic aqueous micellar extraction of trypsin inhibitors and isoflavones from soybean meal: process optimization
}

\author{
Ezequiel R. Coscueta ${ }^{\mathrm{a}, \mathrm{b}, *}$, María Emilia Brassesco a, Luciana Pellegrini Malpiedi ${ }^{\mathrm{b}}$ and Bibiana \\ Beatriz Nerli ${ }^{\text {b }}$

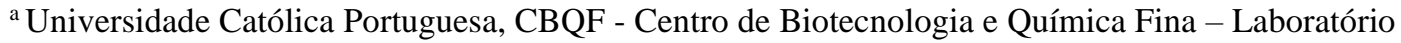
Associado, Escola Superior de Biotecnologia, Rua Diogo Botelho 1327, 4169-005 Porto, Portugal;

${ }^{\mathrm{b}}$ Instituto de Procesos Biotecnológicos y Químicos (IPROBYQ), Consejo Nacional de Investigaciones Científicas y Técnicas (CONICET) - Facultad de Ciencias Bioquímicas y Farmacéuticas, Universidad Nacional de Rosario, Mitre 1998, (S2000FWF) Rosario, Argentina.
\end{abstract}

(*) Corresponding author

Dr. Ezequiel Coscueta

E-mail address: ecoscueta@ucp.pt

Universidade Católica Portuguesa, CBQF - Centro de Biotecnologia e Química Fina - Laboratório Associado, Escola Superior de Biotecnologia, Rua Diogo Botelho 1327, 4169-005 Porto, Portugal

\begin{abstract}
Simultaneous extraction of trypsin inhibitors and soy isoflavones from soybean meal was investigated using the non-destructive phytochemical extraction process, namely aqueous micellar system. The ethoxylated aliphatic alcohols Genapol X-080, Tergitol 15-S-7, and Tergitol 15-S-9, all non-toxic and biodegradable surfactants, were assessed as potential extractants. A Box-Behnken multifactorial design with the application of the Derringer desirability was used to determine the conditions that maximized the trypsin inhibitors and isoflavone extraction while minimizing the protein extraction. The optimum condition of $5 \% \mathrm{~m} / \mathrm{m}$ of surfactant in $50 \mathrm{mM}$ aqueous sodium citrate solution $\mathrm{pH} 4.5$, at $45^{\circ} \mathrm{C}$ for $45 \mathrm{~min}$, was established for the three surfactants. The novel methodology would allow the extraction of the main soybean antinutritional factors, trypsin inhibitors, and the valuable isoflavones, preserving the nutritional quality of the treated material. This represents a sustainable alternative methodology for industrial purposes due to its low cost, biodegradability, nontoxicity, and easy scaling up.
\end{abstract}

KEYWORDS: aqueous micellar system; trypsin inhibitor; isoflavone extraction; non-ionic surfactant; multifactorial optimization

\section{INTRODUCTION}

The Fabaceae family includes plant species that are used by humans, such as legumes used as crops, green manures, and forages. These plants are also used to synthesize a large range of natural products, including flavors, poison, dyes, and have great importance in medicinal purposes (Ahmad, Anwar, \& Hira, 2016). Soybean (Glycine max) is a species of legume native to East Asia cultivated in China since 1000 BC. Over 75\% of global requirements are produced in the USA, Brazil, and Argentina. The annual consumption of soybean has risen from 114 up to 170 million tonnes during the last decade in the world (FAOSTAT, 2020). At present, soybean is one of the most widely grown crops worldwide, of great importance for its nutritional and nutraceutical value (Kulling, Honig, \& Metzler, 2001) and is also used to produce foodstuffs for feeding animals and as an industrial raw material. The derivatives of this vegetable have been studied over the years, recognizing different physiological effects that the phytochemicals can exert it contains (Balisteiro, Rombaldi, \& Genovese, 2013; Coscueta et al., 2016; de Mejia et al., 2021; González-Montoya, Ramón-Gallegos, Robles-Ramírez, \& Mora-Escobedo, 2016). These effects can be both beneficial and harmful, depending on the amount and context of its consumption and the state of the consumer's organism. Among these phytochemicals, we can highlight isoflavones, which have demonstrated very important 
properties for the benefit of cardiovascular and oncological health (Dong, Xu, Sikes, \& Wu, 2013; Filiberto et al., 2013; Park, Ju, Park, \& Han, 2013). Other compounds of great interest are trypsin inhibitors, which represent the main "anti-nutrients" in soybeans (Coscueta et al., 2017). This antinutrient moniker has historically given these protein compounds a very negative reputation, but they may be potentially beneficial for some aspects of human health, such as anticancer and immunomodulating activities (Sadeghalvad, Mohammadi-Motlagh, Karaji, \& Mostafaie, 2019).

This double face of soybeans and their natural phytochemicals has led to the destructive historical processing of these compounds with a focus on improving their nutritional value (Andrade, Mandarino, Kurozawa, \& Ida, 2016; Oliveira et al., 2018; Seo \& Cho, 2016; Yasar, Tosun, \& Sonmez, 2020), with principally isoflavone conversions and inactivation in trypsin inhibitor activity. However, depending on the severity of the conditions employed, thermal processing may negatively affect proteins' digestibility and nutritional value (Hendriks, Bruininx, Gruppen, \& Poel, 2022). This clear loss of value has led to the development of different alternatives for recovering phytochemicals in a non-destructive way (Jackson, Bahri, \& Moheimani, 2017; Mikelová, Zehnálek, Vacek, Kizek, \& Kubá , 2004; Pyo, Yoo, \& Surh, 2009; Ranjha et al., 2021; Terigar et al., 2010), without finding the definitive one yet. Solvent extraction stands out among the vast majority, particularly interested in sustainable solvents (Luthria, Biswas, \& Natarajan, 2007). Among them, extraction with aqueous micellar systems (AMS) has been the subject of study in recent years, proving to be a viable alternative for industrial application, with high efficiency, simplicity, and easy scaling up (Racheva et al., 2018; Vicente et al., 2014; Xu \& He, 2007).

Recently, a wide range of non-toxic, non-inflammable and biodegradable new solvents was for sustainable and green extraction methods (Bajkacz \& Adamek, 2017; Coscueta, Pellegrini Malpiedi, \& Nerli, 2018; Coscueta, Reis, \& Pintado, 2020; Haidar, Coscueta, Cordisco, Nerli, \& Malpiedi, 2018). Certain surfactants fulfill the mentioned properties, thus representing an economical alternative to hazardous, expensive organic solvents. Surfactants are amphiphilic molecules with the ability to form aggregates, namely micelles, that can interact with either hydrophilic or lipophilic molecules through hydrophobic and dipolar interactions and hydrogen bonding, these features being useful for separation purposes (Sharma, Kori, \& Parmar, 2015). In previous works, our research group demonstrated that AMS of Triton X-114 (Cordisco, Haidar, Coscueta, Nerli, \& Malpiedi, 2016) or Genapol X-080 (Coscueta et al., 2018; Haidar et al., 2018) were capable of recovering a high amount of isoflavones from soybean meal under adequate conditions of time, concentration and temperature. Despite this good performance, the UV absorbance signals of Triton X-114, which overlap those of isoflavones, make the analytical evaluation of process progress difficult, this being a disadvantage at an industrial scale. Other surfactants like Genapol X-080, with similar extraction and eco-friendly properties than Triton X-114 but transparent at 240-280 nm spectral range, would be desirable. Ethoxylated primary and secondary aliphatic alcohols belonging to the Tergitol 15-S series possess these characteristics. Regarding the application of Genapol X-080 and Tergitol 15-S systems, we recently demonstrated their suitability for the extraction of other compounds of nutraceutical interest (isothiocyanates) from a complex plant matrix such as watercress (Coscueta et al., 2020).

Based on the preceding results, this work aims to optimize the leaching process of isoflavones and trypsin inhibitors from soybean meal. An experimental design was carried out to find optimal conditions of the extractive process with AMS of Genapol X-080 and Tergitol 15-S that maximize the extraction of trypsin inhibitors and isoflavones from soybean meal, minimizing the extraction of nutritional protein.

\section{MATERIAL AND METHODS}

\subsection{Materials}

The surfactants Genapol X-080, Tergitol 15-S-7, and Tergitol 15-S-9, crystallized salt-free bovine trypsin, and crystalline $\alpha$-N-benzoyl-DL-arginine-p-nitroanilide (BAPNA) were all supplied from Sigma-Aldrich (St. Louis, MO, USA) and used without further purification. Soybean meal was 
supplied by the food processing company Molinos Río de la Plata SA (San Lorenzo, Argentina). All the other reagents were of analytical grade and used without further purification. Deionized water was used to prepare all the solutions.

\subsection{Box-Behnken Design}

The best conditions for extracting the main anti-nutrients from soybean meal by AMS of Genapol X-080, Tergitol 15-S-7, and Tergitol 15-S-9 were determined by statistical analysis. An experimental strategy was implemented to reduce the number of experiments required for process optimization, as well as to establish the most influential factors. For this purpose, a Box-Behnken design was selected, a type of 3-level response surface design that includes a subset of runs of a full factorial at three levels. The factors evaluated were surfactant concentration $\left(\mathrm{X}_{\mathrm{A}}\right)$, temperature $\left(\mathrm{X}_{\mathrm{B}}\right)$, and extraction time $\left(\mathrm{X}_{\mathrm{C}}\right)$. The response variables $(\mathrm{Y})$ were trypsin inhibitory activity (TIA), protein content, and total phenolic content (TPC). Both TIA and protein were expressed as \% considering as $100 \%$ the value obtained from soybean meal according to an alkaline solution (Coscueta et al., 2017). The design resulted in an arrangement of 15 treatments, which was executed in triplicate (a total of 45 experiments) on successive days. The factor levels, coded as -1 (low), 0 (midpoint) and +1 (high), are shown in Table 1.

Table 1. Levels for a Box-Behnken factorial design.

\begin{tabular}{cccc}
\hline & \multicolumn{3}{c}{ Levels } \\
\cline { 2 - 4 } Factor & -1 & 0 & +1 \\
\hline $\mathrm{X}_{\mathrm{A}}{ }^{1}$ & 1 & 5 & 9 \\
$\mathrm{X}_{\mathrm{B}}{ }^{2}$ & 30 & 50 & 70 \\
$\mathrm{X}^{3}$ & 10 & 45 & 80 \\
\hline S Surfactant & concentration in $[\%$ & $\mathrm{m} / \mathrm{m}],{ }^{2}$ \\
temperature in $\left[{ }^{\circ} \mathrm{C}\right]$, and ${ }^{3}$ time in $[\mathrm{min}]$.
\end{tabular}

The experiments were performed with a meal/AMS mass ratio of $10 \% \mathrm{~m} / \mathrm{m}$ in a medium buffered with $50 \mathrm{mM}$ sodium citrate at $\mathrm{pH} 4.5$, mixing the suspensions with a carousel-type stirrer inside a SAN JOR SLDB Series precision incubator. Once the treatments were applied, the systems were centrifuged at $5000 \mathrm{rpm}$ for $5 \mathrm{~min}$ to separate the remaining residue from the supernatant. The precipitates were discarded while the extracts were stored at $-20^{\circ} \mathrm{C}$ for further analysis.

Equation 1 represents the response model considering all linear, quadratic, and linear-linear interaction terms:

$$
\begin{aligned}
\mathrm{Y}=\beta_{0}+\beta_{\mathrm{A}} \mathrm{X}_{\mathrm{A}}+ & \beta_{\mathrm{B}} \mathrm{X}_{\mathrm{B}}+\beta_{\mathrm{C}} \mathrm{X}_{\mathrm{C}}+\beta_{\mathrm{AA}} \mathrm{X}_{\mathrm{A}}^{2}+\beta_{\mathrm{AB}} \mathrm{X}_{\mathrm{A}} \mathrm{X}_{\mathrm{B}}+\beta_{\mathrm{AC}} \mathrm{X}_{\mathrm{A}} \mathrm{X}_{\mathrm{C}}+\beta_{\mathrm{BB}} \mathrm{X}_{\mathrm{B}}^{2}+\beta_{\mathrm{BC}} \mathrm{X}_{\mathrm{B}} \mathrm{X}_{\mathrm{C}} \\
& +\beta_{\mathrm{CC}} \mathrm{X}_{\mathrm{C}}^{2}+\varepsilon
\end{aligned}
$$

where $X_{A}, X_{B}$, and $X_{c}$ are the coded levels of the independent variables mentioned above; $\beta_{0}, \beta_{i}, \beta_{i i}$ and $\beta_{\mathrm{ij}}$ are the regression coefficients for the independent term, linear, quadratic, and binary interaction effects, respectively; and $\varepsilon$, the residual error (Gunst, 1996). Response surface and contour plots of the responses were generated from this model.

The joint optimization of the responses was based on the global desirability function (Derringer \& Suich, 1980). Two important parameters had to be established to define this function: the weight and the impact. The weight defines the shape of the function; when it is 1, the desirability behaves linearly from 0 at the low value to 1 at the high value. For values greater than 1 , it increases 
slowly and then accelerates. If it is very important to approach the maximum level, a large weight can be set.

On the other hand, when some responses are considered more important than others, the impact coefficient is defined by assigning values between 1 and 5. It was considered that TIA should be preponderant over the other responses, focusing on the extraction of the maximum possible trypsin inhibitor content and, therefore, on the detoxification process. For this purpose, the following parameters were established: -a weight of 2 for TIA and of 1 for both protein and TPC; -an impact of 5 for TIA and of value 2 for the other two responses.

\subsection{Analytical determinations}

TIA was measured according to the methodology proposed previously (Coscueta et al., 2017). Absorbance measurements monitored the enzymatic reaction progress at $400 \mathrm{~nm}$ for $2 \mathrm{~min}$. TIA of a given sample was expressed as a percentage of the total TIA present in soybean meal.

The protein content was determined by the bicinchoninic acid method, adapted for use in a 96-well microplate (Smith et al., 1985). A stock bicinchoninic acid (BCA) solution was prepared with this composition: BCA $1.00 \%(\mathrm{~m} / \mathrm{V})$, sodium tartrate $0.16 \%(\mathrm{~m} / \mathrm{V}), \mathrm{Na}_{2} \mathrm{CO}_{3} 2.00 \%(\mathrm{~m} / \mathrm{V}), \mathrm{NaOH}$ $0.40 \%(\mathrm{~m} / \mathrm{V})$, and $\mathrm{NaHCO}_{3} 0.95 \%(\mathrm{~m} / \mathrm{V})$, the final $\mathrm{pH}$ being 11.2. A stock $\mathrm{CuSO}_{4}$ solution of $4.00 \%$ $(\mathrm{m} / \mathrm{V})$ was also prepared. The working BCA reagent was prepared by mixing the BCA stock solution (diluted 1:10) with the stock $\mathrm{CuSO}_{4}$ solution to a 50:1 ratio. The protocol was carried out by placing $25 \mu \mathrm{L}$ of sample in each well and then adding $200 \mu \mathrm{L}$ of working BCA reagent simultaneously in all the wells. The microplate was incubated at $37^{\circ} \mathrm{C}$ for $30 \mathrm{~min}$ before obtaining the absorbance values at $562 \mathrm{~nm}$.

In this work we determined the total phenolic content (TPC) and not directly each isoflavone, but the direct relationship between the TPC and the content of isoflavones in soybean meal was already established in our previous work (Coscueta et al., 2018). The TPC was determined by the Folin-Ciocalteu colorimetric method (V. L. Singleton and J. A. Rossi, 1965) modified as previously reported (Coscueta et al., 2018). Prior to analysis, the protein content of each sample was precipitated with methanol in a $1: 1$ ratio at $-20{ }^{\circ} \mathrm{C}$ over-night and subsequent centrifugation. This was done considering the protein interference with Folin's reagent. The results were expressed as milligrams of gallic acid equivalents per $\mathrm{g}$ of soybean meal $\left[\mathrm{mg} \mathrm{GAE}^{-1}\right]$.

Incubation and absorbance measurements for all the determinations were performed on the Multiskan GO (Thermo Fisher Scientific Corporation) spectrophotometer operated by the SkanIt 3.2 software (Thermo Fisher Scientific Corporation).

\subsection{Statistical analysis}

Each experiment was performed in triplicate, and the results were expressed as the mean values with standard deviations (SD). The means were analyzed statistically by one-way analysis of variance (ANOVA) followed by the Tukey's post-hoc test, by using the least significant difference at the 5\% probability level. The major statistical analysis was carried out with RStudio V 1.0.143.

\section{RESULTS}

Previous work clarified the most important factors and interactions that determine isoflavone extraction performance when using the surfactants studied here, particularly Genapol X-080 (Coscueta et al., 2018). However, a simpler matrix than a soybean meal was the basis for that study. Bearing this in mind, we seek to optimize the extraction process with aqueous micellar systems based on a Box-Behnken-type experimental design. For the analysis of this design, through a response surface model, the responses evaluated were trypsin inhibitory activity (TIA), protein, and total phenolic content (TPC) extracted. Three experimental factors were considered: surfactant concentration $\left(\mathrm{X}_{\mathrm{A}}\right)$, temperature $\left(\mathrm{X}_{\mathrm{B}}\right)$, and extraction time $\left(\mathrm{X}_{\mathrm{C}}\right)$. The appropriate selection of the 
maximum and minimum values for the evaluated factors was made according to our knowledge of the systems.

Table 2 shows the design matrix and the multiple regression results obtained for the 15 randomized treatments. The same criterion mentioned in our previous work with isoflavones was applied for proteins. Thus, the loss of stability of the protein and flavonoid components at high temperature and analysis time and the drastic increase in mean viscosity with surfactant concentration were practical considerations that defined the experimental domain of each factor. The $\mathrm{pH}$ and the mass percentage ratio or meal/AMS ratio were constant parameters. The $\mathrm{pH}$ (4.5) was selected considering the results of the exploratory experiments, being close to the general isoelectric point of the proteins present in soybean meal, where their solubility is minimal (Coscueta et al., 2018). On the other hand, the meal/AMS ratio $(10 \%)$ was established from previous works of the group, thinking mainly about the feasibility of scaling up the process. The graphical representation through Pareto charts (Figure 1) allowed the interpretation of the data obtained.

Table 2. Box-Behnken factorial design for three factors and three responses for AMS of Genapol X080, Tergitol 15-S-7, and Tergitol 15-S-9.

\begin{tabular}{|c|c|c|c|c|c|c|c|c|c|c|c|c|}
\hline \multirow{3}{*}{$\operatorname{Exp}$} & \multicolumn{3}{|c|}{ Factor } & \multicolumn{9}{|c|}{ Response $^{+}$} \\
\hline & \multirow{2}{*}{$\mathrm{X}_{\mathrm{A}^{1}}$} & \multirow{2}{*}{$\mathrm{X}_{\mathrm{B}}{ }^{2}$} & \multirow{2}{*}{$\mathrm{X}_{\mathrm{C}^{3}}$} & \multicolumn{3}{|c|}{ Genapol X-080 } & \multicolumn{3}{|c|}{ Tergitol 15-S-7 } & \multicolumn{3}{|c|}{ Tergitol 15-S-9 } \\
\hline & & & & TIA $^{4}$ & $\mathrm{Pt}^{5}$ & TPC $^{6}$ & TIA $^{4}$ & $\mathrm{Pt}^{5}$ & TPC $^{6}$ & TIA $^{4}$ & $\mathrm{Pt}^{5}$ & TPC $^{6}$ \\
\hline 1 & 1 & 30 & 45 & $83 \pm 4$ & $36 \pm 3$ & $1.51 \pm 0.12$ & $85 \pm 6$ & $34 \pm 2$ & $1.30 \pm 0.08$ & $75 \pm 4$ & $39 \pm 3$ & $1.31 \pm 0.07$ \\
\hline 2 & 9 & 30 & 45 & $73 \pm 5$ & $33 \pm 3$ & $1.72 \pm 0.09$ & $81 \pm 5$ & $34 \pm 2$ & $1.59 \pm 0.10$ & $65 \pm 5$ & $29 \pm 2$ & $1.52 \pm 0.07$ \\
\hline 3 & 5 & 30 & 80 & $99 \pm 6$ & $44 \pm 3$ & $1.79 \pm 0.12$ & $93 \pm 6$ & $38 \pm 2$ & $1.59 \pm 0.10$ & $83 \pm 7$ & $38 \pm 1$ & $1.52 \pm 0.06$ \\
\hline 4 & 5 & 50 & 45 & $94 \pm 5$ & $38 \pm 2$ & $1.85 \pm 0.08$ & $93 \pm 5$ & $39 \pm 2$ & $1.63 \pm 0.08$ & $89 \pm 9$ & $37 \pm 2$ & $1.58 \pm 0.04$ \\
\hline 5 & 9 & 50 & 10 & $83 \pm 6$ & $29 \pm 2$ & $1.48 \pm 0.09$ & $65 \pm 5$ & $30 \pm 2$ & $1.53 \pm 0.09$ & $61 \pm 4$ & $38 \pm 2$ & $1.34 \pm 0.09$ \\
\hline 6 & 5 & 50 & 45 & $101 \pm 4$ & $40 \pm 1$ & $1.84 \pm 0.15$ & $100 \pm 2$ & $39 \pm 2$ & $1.62 \pm 0.10$ & $88 \pm 6$ & $40 \pm 3$ & $1.59 \pm 0.03$ \\
\hline 7 & 1 & 50 & 10 & $97 \pm 7$ & $31 \pm 2$ & $1.43 \pm 0.09$ & $68 \pm 4$ & $31 \pm 2$ & $1.26 \pm 0.08$ & $65 \pm 4$ & $40 \pm 2$ & $1.28 \pm 0.08$ \\
\hline 8 & 9 & 50 & 80 & $91 \pm 6$ & $36 \pm 2$ & $1.78 \pm 0.14$ & $87 \pm 5$ & $37 \pm 2$ & $1.54 \pm 0.08$ & $77 \pm 8$ & $31 \pm 2$ & $1.54 \pm 0.06$ \\
\hline 9 & 5 & 70 & 10 & $89 \pm 6$ & $33 \pm 2$ & $1.35 \pm 0.08$ & $68 \pm 4$ & $29 \pm 2$ & $1.37 \pm 0.09$ & $57 \pm 4$ & $32 \pm 2$ & $1.31 \pm 0.04$ \\
\hline 10 & 5 & 70 & 80 & $74 \pm 5$ & $35 \pm 3$ & $1.50 \pm 0.13$ & $81 \pm 4$ & $35 \pm 2$ & $1.32 \pm 0.07$ & $73 \pm 4$ & $30 \pm 2$ & $1.39 \pm 0.06$ \\
\hline 11 & 9 & 70 & 45 & $63 \pm 5$ & $28 \pm 3$ & $1.46 \pm 0.08$ & $78 \pm 5$ & $31 \pm 2$ & $1.55 \pm 0.06$ & $59 \pm 4$ & $26 \pm 2$ & $1.29 \pm 0.07$ \\
\hline 12 & 1 & 50 & 80 & $94 \pm 6$ & $36 \pm 3$ & $1.66 \pm 0.10$ & $92 \pm 7$ & $35 \pm 2$ & $1.35 \pm 0.08$ & $83 \pm 5$ & $49 \pm 4$ & $1.32 \pm 0.09$ \\
\hline 13 & 5 & 30 & 10 & $89 \pm 8$ & $33 \pm 3$ & $1.49 \pm 0.12$ & $69 \pm 6$ & $31 \pm 2$ & $1.41 \pm 0.10$ & $66 \pm 4$ & $38 \pm 3$ & $1.33 \pm 0.08$ \\
\hline 14 & 5 & 50 & 45 & $94 \pm 3$ & $37 \pm 2$ & $1.80 \pm 0.10$ & $93 \pm 2$ & $39 \pm 1$ & $1.61 \pm 0.04$ & $88 \pm 4$ & $38 \pm 3$ & $1.60 \pm 0.04$ \\
\hline 15 & 1 & 70 & 45 & $61 \pm 4$ & $30 \pm 3$ & $1.50 \pm 0.12$ & $81 \pm 6$ & $31 \pm 2$ & $1.25 \pm 0.06$ & $70 \pm 5$ & $31 \pm 2$ & $1.44 \pm 0.08$ \\
\hline
\end{tabular}

${ }^{+}$Values expressed as mean $\pm \mathrm{SD}$ of three replicates. ${ }^{1}$ Surfactant concentration in $[\% \mathrm{~m} / \mathrm{m}],{ }^{2}$ temperature in $\left[{ }^{\circ} \mathrm{C}\right] \mathrm{y}^{3}$ time in [min]. ${ }^{4} \mathrm{TIA}$ in [\%], ${ }^{5}$ Protein in [\%], and ${ }^{6} \mathrm{TPC}$ in [mg GAE g-1].

Figure 1 shows that the effects were not equally significant between surfactants for any responses. Considering TIA (Figure 1A, B, and C), practically all three factors were significant, although their interactions were not. Genapol X-080 system was more sensitive to temperature and concentration, whereas Tergitol 15-S-7 and Tergitol 15-S-9 systems were more sensitive to time. In general, considering the extreme values of the variables, the higher the concentration and temperature, the lower the TIA, while this response increases with time. However, at intermediate values in the factor ranges, TIA increases until it reaches a maximum and then decreases again. Neither time presents a significant linear effect for Genapol X-080 nor concentration for Tergitol 15-S-7, meaning that between the extreme values of these factors, we do not find a difference in response. Therefore, it can be said that maximum TIA values are reached at intermediate values of the ranges tested for 
each variable. The adjusted coefficients of determination $\left(\mathrm{R}^{2}{ }_{\text {adj }}\right)$ for the three initial models indicated that they explained more than $80 \%$ of the variability of the data obtained for TIA $\left(\mathrm{R}^{2}{ }_{\text {adj }}=0.822\right.$ for Genapol X-080, 0.809 for Tergitol 15-S-7, and 0.807 for Tergitol 15-S-9), which accounts for the good predictive consistency of each model.
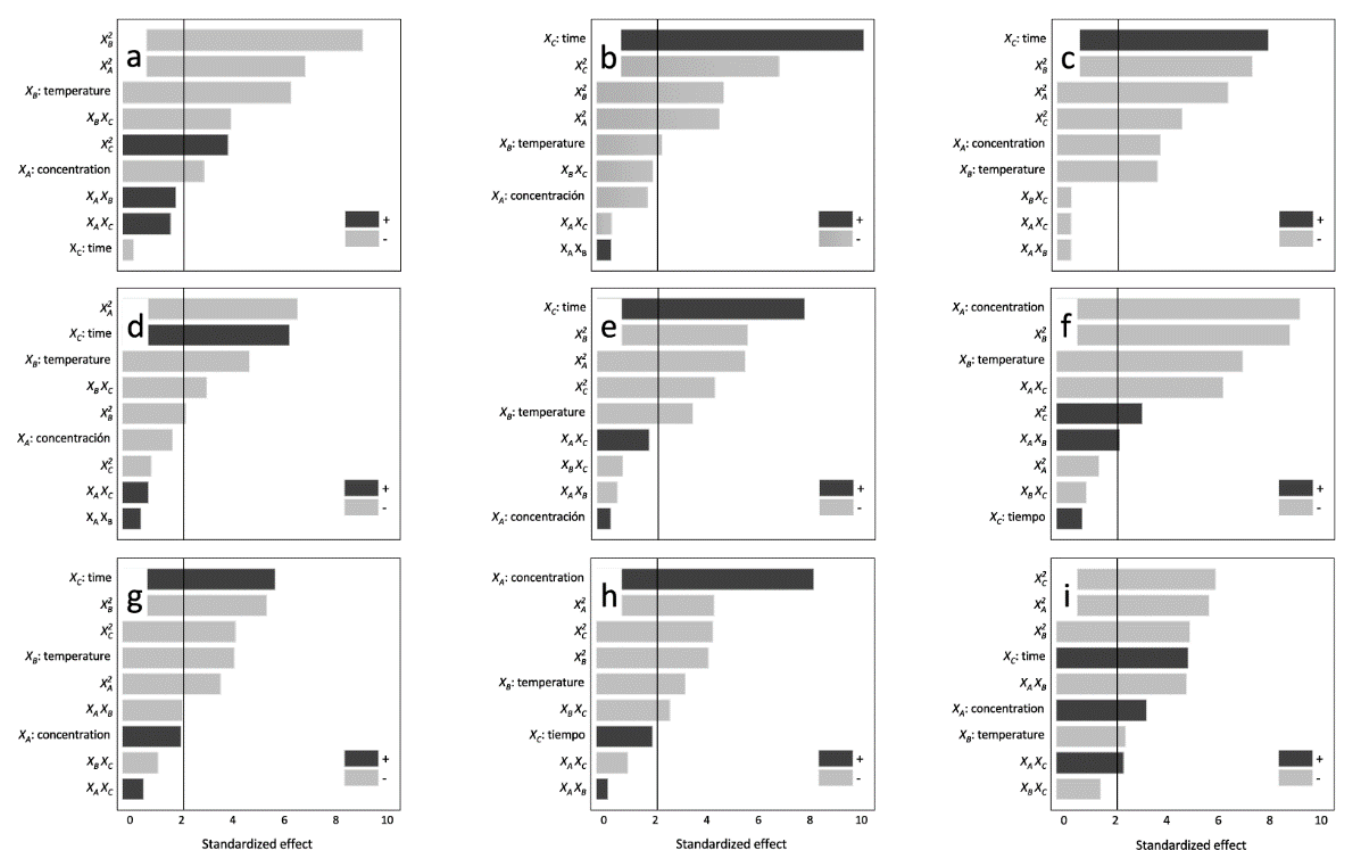

Figure 1. Effect analysis of the Box-Behnken factorial design. Standardized Pareto charts with effects of three experimental factors, decreasing order of importance. Response: TIA for Genapol X-080 (a), Tergitol 15-S-7 (b), and Tergitol 15-S-9 (c); Protein for Genapol X-080 (d), Tergitol 15-S-7 (e), and Tergitol 15-S-9 (f); TPC for Genapol X-080 (g), Tergitol 15-S-7 (h), and Tergitol 15-S-9 (i). The black vertical lines represent the significance threshold $(\mathrm{P}=0.05)$.

For protein (Figure 1D, E, and F), the effects of the factors are like those for TIA, where all three variables are significant for the models, and their interactions are not noticeable. In general, for all three surfactants, the effects of the factors act quadratically, growing to a maximum, as described in the previous paragraph. The exception in this sense was presented for Tergitol 15-S-9 since time, instead of making the response grow to a maximum within the evaluated range, makes it decrease to a minimum without showing differences between the extreme values of the interval. Like TIA, we can say that within the tested ranges of each variable, maximum protein values are reached. This is consistent with the fact that trypsin inhibitors are part of the protein content. The $\mathrm{R}^{2}$ adj for the three initial models indicated they explained more than $72 \%$ of the variability of the data obtained for the proteins $\left(\mathrm{R}_{\text {adj }}^{2}=0.727\right.$ for GX, 0.769 for Tergitol 15-S-7, and 0.853 for Tergitol 15-S-9), which for the complex matrix with used allowed us to consider the adjusted model as adequate.

In the case of the TPC (Figure 1G, H, and I), once again, we observed a clear sign of the three experimental factors. The difference we can find with the models for the other two responses is that the concentration for Tergitol 15-S-7 and Tergitol 15-S-9 produced a greater response at their maximum end than at their lowest value, accounting for a positive sense of their linear effect. However, a maximum continues to be found towards intermediate values of the analyzed interval. Particularly for Genapol X-080, the concentration does not present different TPC values between its extremes $(1$ and $9 \% \mathrm{~m} / \mathrm{m})$, different from what was observed in the previous work for the commercial tablets, where we found a maximum of $11 \% \mathrm{~m} / \mathrm{m}$ within an interval of $3-17 \% \mathrm{~m} / \mathrm{m}$ (Coscueta et al., 2018). We also say that TPC finds a maximum at an intermediate value of the range analyzed for each response. Once again, the model showed correct representativeness of the data, as could be 
inferred from the $\mathrm{R}_{\text {adj }}^{2}$, indicating an explanation of more than $70 \%$ of the variability $\left(\mathrm{R}_{\text {adj }}^{2}=0.705\right.$ for GX, 0.734 for Tergitol 15-S-7, and 0.749 for Tergitol 15-S-9).

The models were then recalculated, eliminating some of the non-significant effects with the criterion of maximizing the $\mathrm{R}^{2}$ adj, adjusting again from the multiple regression of the data. The results of the final models can be seen in Table 3, including the regression statistics obtained for the models: lack of fit test, $\mathrm{R}^{2}, \mathrm{R}^{2}$ adj, and RSD.

Table 3. Best estimates of the coefficients $\left(\beta_{0}, \beta_{\mathrm{i}}\right.$, and $\left.\beta_{\mathrm{ij}}\right)$ and the corresponding statistics, about the three responses evaluated for SMAs of the surfactants Genapol X-080, Tergitol 15-S-7, and Tergitol 15-S-9.

\begin{tabular}{|c|c|c|c|c|c|c|c|c|c|}
\hline \multirow{3}{*}{ Term } & \multicolumn{9}{|c|}{ Estimates $^{+}$} \\
\hline & \multicolumn{3}{|c|}{ Genapol X-080 } & \multicolumn{3}{|c|}{ Tergitol 15-S-7 } & \multicolumn{3}{|c|}{ Tergitol 15-S-9 } \\
\hline & TIA & Protein & ТPC & TIA & Protein & TPC & TIA & Protein & TPC \\
\hline Constant & 9.3056 & 16.2411 & 0.0951 & 8.4163 & 11.2856 & 0.4324 & -5.7722 & 13.9516 & 0.3103 \\
\hline $\mathrm{X}_{\mathrm{A}}$ & $3.6973^{* *}$ & 2.8417 & 0.1191 & 3.8569 & 1.6352 & $0.0960^{* * * *}$ & $5.1814^{* * * *}$ & $-0.0633^{* * * x}$ & $0.1186^{* * *}$ \\
\hline Хв & $3.6444^{* * * *}$ & $0.4196^{* *+4}$ & $0.0438^{*+*}$ & $1.8382^{*}$ & $0.7218^{8 * *}$ & $0.0252^{2 * *}$ & $2.6374^{4 * *}$ & $1.2599^{* * * *}$ & $0.0289^{*}$ \\
\hline $\mathrm{X}_{\mathrm{c}}$ & -0.1068 & $0.2462^{* * *+}$ & $0.0154^{* * *+}$ & $1.2642^{* * *+}$ & $0.2307^{* *+4}$ & 0.0124 & $0.7590^{* * *+}$ & -0.0069 & $0.0104^{* * *}$ \\
\hline $\mathrm{X}_{\mathrm{A}^{2}}$ & $-0.7087^{* * *+}$ & $-0.3055^{* * * *}$ & $-0.0070^{* * *}$ & $-0.4294^{* * *+}$ & $-0.1938^{* * *+}$ & $-0.0063^{* *+x}$ & $-0.6162^{* * * *}$ & -0.0584 & $-0.0067^{* * *+1}$ \\
\hline $\mathrm{X}_{\mathrm{A}} \mathrm{X}_{\mathrm{B}}$ & 0.0355 & - & -0.0008 & - & - & - & - & $0.0178^{*}$ & $-0.0011^{* * * *}$ \\
\hline $\mathrm{X}_{\mathrm{A}} \mathrm{X}_{\mathrm{C}}$ & 0.0179 & - & - & - & 0.0067 & - & - & $-0.0293^{* *+*}$ & $0.0003^{*}$ \\
\hline $\mathrm{X}_{\mathrm{B}^{2}}$ & $-0.0377^{*+*+1}$ & $-0.0040^{*}$ & $-0.0004^{*+*+}$ & $-0.0178^{* * *}$ & $-0.0079^{* *+*}$ & $-0.0002^{* *+*}$ & $-0.0283^{* * *+}$ & $-0.0151^{* * *+}$ & $-0.0002^{* * * *}$ \\
\hline $\mathrm{X}_{\mathrm{B}} \mathrm{X}_{\mathrm{C}}$ & $-0.0090^{*+*+\infty}$ & $-0.0031^{* *}$ & -0.0001 & -0.0040 & - & $-0.0001^{*}$ & - & - & -0.0001 \\
\hline $\mathrm{X}_{\mathrm{C}^{2}}$ & $0.0052^{*+*}$ & - & $-0.0001^{*+*+1}$ & $-0.0085^{* \ldots+}$ & $-0.0020^{* * *+}$ & $-0.0001^{* * *+}$ & $-0.0058^{* * *+}$ & $0.0017^{* *}$ & $-0.0001^{* * *}$ \\
\hline \multicolumn{10}{|c|}{ Statistics } \\
\hline Lack of fit ${ }^{1}$ & 0.587 & 0.922 & 0.864 & 0.818 & 0.895 & 0.482 & 0.847 & 0.285 & 0.207 \\
\hline $\mathrm{R}^{22}$ & 0.858 & 0.774 & 0.763 & 0.848 & 0.812 & 0.783 & 0.845 & 0.879 & 0.801 \\
\hline $\mathrm{R}^{2}{ }_{\mathrm{adj}^{3}}$ & 0.827 & 0.739 & 0.711 & 0.819 & 0.782 & 0.742 & 0.821 & 0.856 & 0.749 \\
\hline $\mathrm{RSD}^{4}$ & 5.565 & 2.521 & 0.106 & 5.097 & 1.844 & 0.079 & 5.168 & 2.257 & 0.064 \\
\hline
\end{tabular}

${ }^{\dagger}$ Effects significantly different from zero: ${ }^{*} \mathrm{P}<0.050,{ }^{* *} \mathrm{P}<0.010,{ }^{* * *} \mathrm{P}<0.001 .{ }^{1}$ Test for lack of fit expressed at its test value $(\mathrm{P}) .{ }^{2} \mathrm{R}^{2}=$ determination coefficient. ${ }^{3} \mathrm{R}^{2}$ adj $=$ adjusted determination coefficient. ${ }^{4} \mathrm{RSD}=$ standard deviation of the residuals.

The new models continued to adequately explain the variation in each response, with a maximization of the corresponding $\mathrm{R}_{\text {adj. }}^{2}$. Figure 2 shows the response surfaces of the final models, expressing the responses as a function of the factors considered for each surfactant.

Looking at the surfaces for TIA, as mentioned in the analysis of the direction of the effects in the initial model, average values of surfactant concentration and temperature led to a maximum of the response for all three surfactants. However, time showed a different effect on GENAPOL X-080, Tergitol 15-S-7, and Tergitol 15-S-9. For Genapol X-080, the linear effect $\mathrm{X}_{\mathrm{C}}$ was neglected in the recalculated model, and $\mathrm{X}_{\mathrm{C}}{ }^{2}$ led to minimum responses towards central values, although with a little pronounced curvature, indicating a reduced influence of time. In the case of Tergitol 15-S-7 and Tergitol 15-S-9, the maximum TIA is obtained at values close to the higher level of time.

The fitted models predicted maximum TIA of $106 \pm 12 \%, 99 \pm 11 \%$, and $92 \pm 11 \%$ for Genapol X-080, Tergitol 15-S-7, and Tergitol 15-S-9, respectively. The optimum conditions in the application of AMS would be $4.6 \% \mathrm{~m} / \mathrm{m}$ at $41{ }^{\circ} \mathrm{C}$ for $80 \mathrm{~min}$ (Genapol X-080), $4.5 \% \mathrm{~m} / \mathrm{m}$ at $45{ }^{\circ} \mathrm{C}$ for $64 \mathrm{~min}$ (Tergitol 15-S-7), and $4.2 \% \mathrm{~m} / \mathrm{m}$ at $47^{\circ} \mathrm{C}$ for $66 \mathrm{~min}$ (Tergitol 15-S-9). 

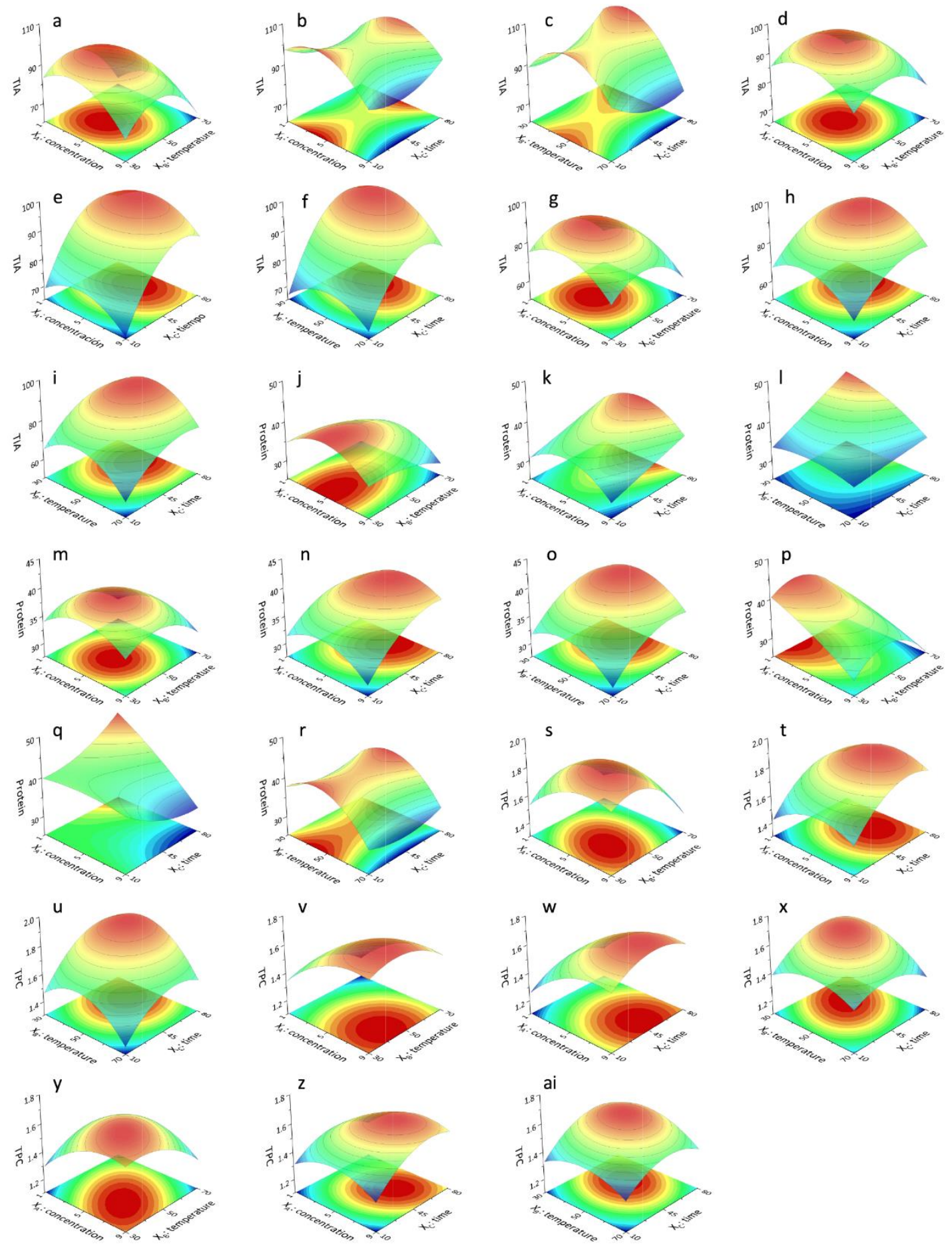

Figure 2. Response surfaces estimated as a function of two experimental factors, keeping the third factor at its central value. Response: TIA for Genapol X-080 (a, b, c), Tergitol 15-S-7 (d, e, f), and Tergitol 15-S-9 (g, h, i); Protein for Genapol X-080 (j, k, l), Tergitol 15-S-7 (m, n, o), and Tergitol 15-S-9 (p, q, r); TPC for Genapol X080 (s, t, u), Tergitol 15-S-7 (v, w, x), and Tergitol 15-S-9 (y, z, ai). 
Protein is the response for which we found the greatest differences in behavior between the surfactants. The graphs in Figure 2 reaffirm for Genapol X-080 and Tergitol 15-S-7, the concentration-effect leads to reach a maximum of the response at intermediate levels of the factor. $\mathrm{X}_{\mathrm{A}}$ was negligible for Genapol X-080 and was even neglected from the model for Tergitol 15-S-7, so the major influence is given by the quadratic effect of the factor. Tergitol 15-S-9, on the other hand, showed a protein maximum at the lowest concentration, with an almost linear reduction of the response with increasing factor. The effects of temperature cause similar behaviors for Genapol X080, Tergitol 15-S-7, and Tergitol 15-S-9 but with different predominance in the model, making the general effect particular to each surfactant. For Genapol X-080, $\mathrm{X}_{\mathrm{B}}$ predominated, generating an almost linear reduction in the response as the factor increased, presenting only a slight curvature.

On the other hand, for both Tergitol 15-S-7 and Tergitol 15-S-9 $X_{B}$ influenced mainly by its quadratic effects, maximizing the response between intermediate to lower levels of temperature and reaching a minimum towards the higher level of the factor. On the other hand, while for Genapol X080 and Tergitol 15-S-7 time produced a directly proportional response, with linear growth for the Genapol X-080 ( $\mathrm{X}_{\mathrm{C}}^{2}$ neglected from the model) and slightly curved for Tergitol 15-S-7, for Tergitol $15-S-9$, as distinguished in the initial model, the factor minimized the response towards the central level. Moreover, in the case of Genapol X-080, the effect of temperature was minimal at a low level of time, while at high levels, it increased, reflecting the importance of the $\mathrm{X}_{\mathrm{B}} \mathrm{X}_{\mathrm{C}}$ interaction. Something similar happened with Tergitol 15-S-9, but for the case of the $X_{A} X_{C}$ interaction, where the longer the time, the greater the concentration effect.

The adjusted models predicted minimum values of $27 \pm 6 \%, 25 \pm 4 \%$, and $23 \pm 5 \%$ for protein content, respectively, with Genapol X-080, Tergitol 15-S-7, and Tergitol 15-S-9. Optimal conditions in the application of AMS would be $9.0 \% \mathrm{~m} / \mathrm{m}$ at $70{ }^{\circ} \mathrm{C}$ for $10 \mathrm{~min}$ (Genapol X-080), $9.0 \% \mathrm{~m} / \mathrm{m}$ at $70{ }^{\circ} \mathrm{C}$ for $10 \mathrm{~min}$ (Tergitol 15-S-7) and $9.0 \% \mathrm{~m} / \mathrm{m}$ at $70{ }^{\circ} \mathrm{C}$ for $80 \mathrm{~min}$ (Tergitol $15-\mathrm{S}-9$ ).

The temperature-related effect observed for both protein and TIA indicated that the minimum values of the responses are always toward the maximum of that factor, which is attributed to the protein denaturation that occurs at such a high temperature $\left(70{ }^{\circ} \mathrm{C}\right)$.

Concerning TPC, the behavior observed for the three systems (Figure 2) was quite similar. In general, concentration maximized the response at values between the central and the higher levels, while temperature did the same between the central and lower levels. For Tergitol 15-S-7, the decay of the response at higher temperatures was less drastic than that observed for the other two surfactants, making the linear $X_{B}$ effect less important. The interaction effect between concentration and temperature was considerable, especially for Genapol X-080 and Tergitol 15-S-9, indicating that the first factor's linear effect is reversed at high temperatures, presenting minimum TPC at high surfactant concentration. Time was the most influential factor overall, with a linear preponderant impact for Genapol X-080 and Tergitol 15-S-9. Increasing the processing time increases the response, this change being greater at low factor levels.

From the models adjusted for TPC, maximum values of $1.88 \pm 0.22 \mathrm{mg} \mathrm{GAE} \mathrm{g}^{-1}, 1.67 \pm 0.17$

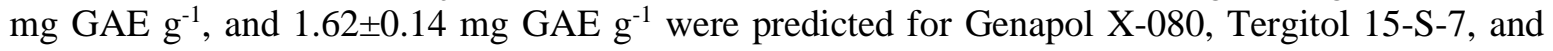
Tergitol 15-S-9, respectively. The optimum conditions in the application of AMS would be $6.2 \%$ $\mathrm{m} / \mathrm{m}$ at $43{ }^{\circ} \mathrm{C}$ for $63 \mathrm{~min}$ (genapol X-080), $7.6 \% \mathrm{~m} / \mathrm{m}$ at $43{ }^{\circ} \mathrm{C}$ for $54 \mathrm{~min}$ (Tergitol 15-S-7), and 6.8 $\% \mathrm{~m} / \mathrm{m}$ at $41{ }^{\circ} \mathrm{C}$ for $60 \mathrm{~min}$ (Tergitol 15-S-9). If we compare the resulting model for Genapol X-080 with the one calculated in the previously reported work (Coscueta et al., 2018), we can see the optimum conditions are different, being at lower surfactant concentration ( $40 \%$ lower $)$ and lower temperature $\left(\sim 10^{\circ} \mathrm{C}\right.$ lower). This accounts for the importance of the matrix and the need to optimize particularly for each matrix to work. Furthermore, it should be clarified that there is a notable difference between the optimal TPC predicted here and the one obtained in the previous work. The different meal/AMS ratios $(10 \% \mathrm{~m} / \mathrm{m}$ in the present section and $2 \% \mathrm{~m} / \mathrm{m}$ in the previous one) may explain this, being the lower the percentage, the higher the TPC obtained per unit of meal mass. 
Desirability functions were then estimated. The "Derringer desirability" (general desirability) function (Derringer \& Suich, 1980) helps to determine the combination of the experimental factors that simultaneously optimizes several responses. General desirability was achieved by considering TIA as the most important response, which together with TPC were maximized, while protein was minimized. Figure 3 shows desirability prediction surfaces, estimated as a function of the three studied factors. Initially, the optimum desirability was calculated separately for each surfactant, thus obtaining ideal conditions for each system. The highest predicted desirability was obtained for Genapol X-080 (0.810), being considerably lower for Tergitol 15-S-7 (0.656) and Tergitol 15-S-9 (0.530). The conditions corresponding to these optimum values were $4.7 \% \mathrm{~m} / \mathrm{m}$ at $48{ }^{\circ} \mathrm{C}$ for $20 \mathrm{~min}$ for Genapol X-080, $5.3 \% \mathrm{~m} / \mathrm{m}$ at $43{ }^{\circ} \mathrm{C}$ for $61 \mathrm{~min}$ for Tergitol $15-\mathrm{S}-7$, and $5.6 \% \mathrm{~m} / \mathrm{m}$ at $47{ }^{\circ} \mathrm{C}$ for $61 \mathrm{~min}$ for Tergitol 15-S-9. This would yield respective values for Genapol X-080, Tergitol 15-S-7 and Tergitol 15-S-9: -TIA of 100\%, 98\%, and 90\%; -Pt of 36\%, 40\%, and 38\%; -TPC of $1.68 \mathrm{mg}$ $\mathrm{GAE}^{-1}, 1.64 \mathrm{mg} \mathrm{GAE} \mathrm{g}^{-1}$, and $1.61 \mathrm{mg} \mathrm{GAE} \mathrm{g}^{-1}$.
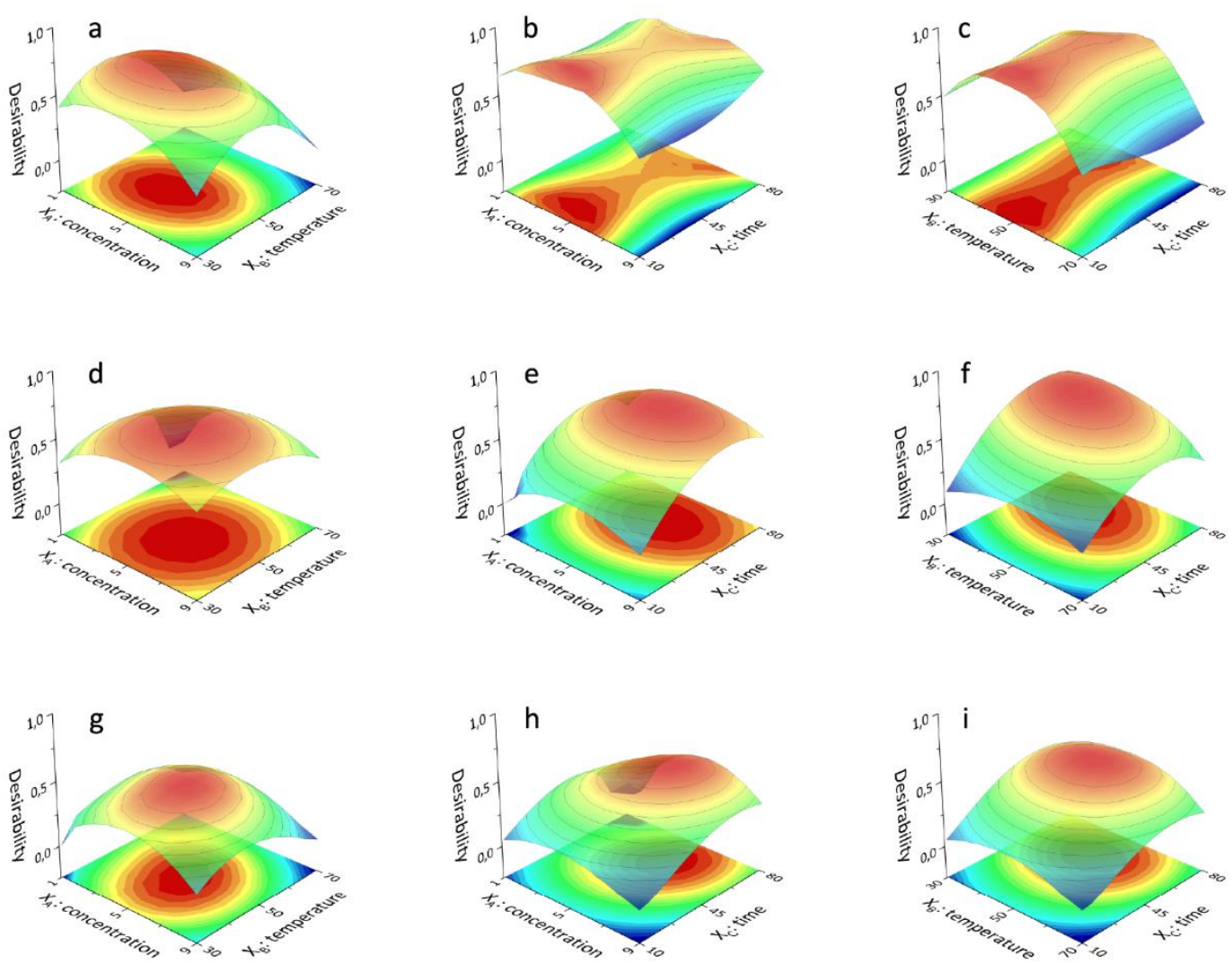

Figure 3. Desirability surfaces estimated as a function of two experimental factors keeping the third factor at its central value. Response: TIA for Genapol X-080 (a), Tergitol 15-S-7 (b), and Tergitol 15-S-9 (c); Protein for Genapol X-080 (d), Tergitol 15-S-7 (e), and Tergitol 15-S-9 (f); TPC for Genapol X-080 (g), Tergitol 15S-7 (h), and Tergitol 15-S-9 (i).

Then, other possibilities were explored, envisioning the possibility of designing a unified process independently of the surfactant used (among those studied). The intermediate condition of $5 \% \mathrm{~m} / \mathrm{m}$ surfactant at $45{ }^{\circ} \mathrm{C}$ for $45 \mathrm{~min}$ was then considered. The predicted values were desirability $=0.751$, TIA $=97 \pm 12 \%$, Protein $=39 \pm 5 \%$, and TPC $=1.84 \pm 0.23 \mathrm{mg} \mathrm{GAE} \mathrm{g}^{-1}$ for Genapol X-080; desirability $=0.620$, TIA $=95 \pm 11 \%$, Protein $=38 \pm 4 \%$, and TPC $=1.63 \pm 0.17 \mathrm{mg} \mathrm{GAE} \mathrm{g}^{-1}$ for Tergitol 
15-S-7; desirability $=0.482$, TIA $=89 \pm 11 \%$, Protein $=39 \pm 5 \%$, and TPC $=1.59 \pm 0.14 \mathrm{mg} \mathrm{GAE} \mathrm{g}^{-1}$ for Tergitol 15-S-9. These values were not statistical different among themselves, being the global means TIA $=94 \%$, Protein $=39 \%$, and TPC $=1.69 \mathrm{mg} \mathrm{GAE} \mathrm{g}^{-1}$. These predictions indicate the unified condition would allow desirable results that do not depart from the individually predicted optimum. Likewise, this provides the desired scenario of flexible technology, applicable more generally and not restricted to a particular surfactant.

\section{DISCUSSION}

In previous work, we established the interaction between Genapol X-080, Tergitol 15-S-7, and Tergitol 15-S-9 and isoflavones, demonstrating that the three surfactants tested here presented better extractive qualities of these phytochemicals compared to other surfactants and even with traditional organic solvents, highlighting the performance of Genapol X-080. Following, the current work optimized AMS of Genapol X-080, Tergitol 15-S-7, and Tergitol 15-S-9 in the extraction of trypsin inhibitors and isoflavones, with reduced protein extraction from soybean meal. By performing multiple optimizations, desirable conditions were found $\left(5 \% \mathrm{~m} / \mathrm{m}\right.$ surfactant, $\mathrm{pH} 4.5$ at $45^{\circ} \mathrm{C}$ for 45 $\mathrm{min}$ ), applicable to all three surfactants with similar predicted results. It is important to mention the appropriateness of using robust statistical tools in the optimization process. These are complex systems strongly affected by different variables and their interactions, being practically unfeasible to predict accurate behaviors based on the classical unifactorial method (one variable at a time). Also, note how difficult it is to find a convincing physical explanation for the effect caused by each variable in the analyzed response. To take the dimension of the mentioned complexity, it is enough to consider one of these variables as an example, such as temperature and its potential actions in extracting a given analyte. This can affect the stability of the molecule of interest. The release process by breaking interactions of that substance from the matrix that contains it determines the speed of the diffusive process towards the extract, and in the case of surfactant systems, it also influences micellar properties. This is related to the fact that the proposed models fail to explain between 15 and $25 \%$ of the data variability.

The use of thermal treatment (Andrade et al., 2016) or conventional extraction with hazardous, expensive organic solvents (Murphy, Barua, \& Hauck, 2002) has led to obtaining comparable phytochemical inactivation/extraction but destructively and modifying the final product protein profile.

Finally, having achieved an optimum condition, common to all three surfactants, positions the AMS as potentially applicable in a wide range of liquid-solid extractions. Thus, applying this process in the detoxification of white soybean meal, followed by a phase separation step to give rise to aqueous two-phase systems, could allow extracting, concentrating, and purifying antinutritional factors and isoflavones, and obtaining as a final product a protein concentrate with good nutritional and bio-functional characteristics. Furthermore, the possibility of substituting organic solvents with these biodegradable, non-flammable, and non-toxic agents, and the possible application in large-scale extraction procedures, make AMS suitable for industrial purposes. From a future perspective, we propose to apply the optimal conditions on a larger scale to validate the model. In addition, a physicochemical, nutritional, and nutraceutical characterization of the product and by-products, considering other important antinutrients such as indigestible oligosaccharides, functional properties, protein quality, and potential bioactivities.

\section{CONCLUSION}

The non-ionic aqueous micellar extraction technology effectively extracted trypsin inhibitor and isoflavones from soybean meal simultaneously. The use of non-toxic, non-inflammable, and biodegradable surfactants positively influenced the extraction of trypsin inhibitors and isoflavones. Using an appropriate multifactorial experimental design and robust statistical tools, we optimized the process. We maximized the extraction of trypsin inhibitors and isoflavones while minimizing the 
leaching of nutritional proteins. Moreover, the optimal conditions proposed were independent of the surfactant applied (global response means TIA $=94 \%$, Protein $=39 \%$, and TPC $=1.69 \mathrm{mg} \mathrm{GAE} \mathrm{g}^{-1}$ ) accounting for technological flexibility. Thus, the proposed methodology could be a technologically and economically viable alternative to the more aggressive methodologies currently applied.

\section{REFERENCES}

Ahmad, F., Anwar, ; \& Hira, ; (2016). Review on medicinal importance of fabaceae family. PhOL, 3, 151-156. Retrieved from http://pharmacologyonline.silae.it

Andrade, J. C., Mandarino, J. M. G., Kurozawa, L. E., \& Ida, E. I. (2016). The effect of thermal treatment of whole soybean flour on the conversion of isoflavones and inactivation of trypsin inhibitors. Food Chemistry, 194, 1095-1101. https://doi.org/10.1016/j.foodchem.2015.08.115

Bajkacz, S., \& Adamek, J. (2017). Evaluation of new natural deep eutectic solvents for the extraction of isoflavones from soy products. Talanta, 168, 329-335. https://doi.org/10.1016/j.talanta.2017.02.065

Balisteiro, D. M., Rombaldi, C. V., \& Genovese, M. I. (2013). Protein, isoflavones, trypsin inhibitory and in vitro antioxidant capacities: Comparison among conventionally and organically grown soybeans. Food Research International, 51(1), 8-14. https://doi.org/10.1016/j.foodres.2012.11.015

Cordisco, E., Haidar, C. N., Coscueta, E. R., Nerli, B. B., \& Malpiedi, L. P. (2016). Integrated extraction and purification of soy isoflavones by using aqueous micellar systems. Food Chemistry, 213, 514-520. https://doi.org/10.1016/j.foodchem.2016.07.001

Coscueta, E. R., Amorim, M. M., Voss, G. B., Nerli, B. B., Picó, G. A., \& Pintado, M. E. (2016). Bioactive properties of peptides obtained from Argentinian defatted soy flour protein by Corolase PP hydrolysis. Food Chemistry, 198, 36-44. https://doi.org/10.1016/j.foodchem.2015.11.068

Coscueta, E. R., Pellegrini Malpiedi, L., \& Nerli, B. B. (2018). Micellar systems of aliphatic alcohol ethoxylates as a sustainable alternative to extract soybean isoflavones. Food Chemistry, 264, 135-141. https://doi.org/10.1016/j.foodchem.2018.05.015

Coscueta, E. R., Pintado, M. E., Picó, G. A., Knobel, G., Boschetti, C. E., Malpiedi, L. P., \& Nerli, B. B. (2017). Continuous method to determine the trypsin inhibitor activity in soybean flour. Food Chemistry, 214, 156-161. https://doi.org/10.1016/j.foodchem.2016.07.056

Coscueta, E. R., Reis, C. A., \& Pintado, M. (2020). Phenylethyl Isothiocyanate Extracted from Watercress By-Products with Aqueous Micellar Systems: Development and Optimisation. Antioxidants, 9(698), 1-11. https://doi.org/10.3390/antiox9080698

de Mejia, E. G., Castañeda-Reyes, E. D., Mojica, L., Dia, V., Wang, H., Wang, T., \& Johnson, L. A. (2021). Potential health benefits associated with lunasin concentration in dietary supplements and lunasin-enriched soy extract. Nutrients, 13(5), 1618. https://doi.org/10.3390/nu13051618

Derringer, G., \& Suich, R. (1980). Simultaneous Optimization of Several Response Variables. Journal of Quality Technology, 12(4), 214-219. https://doi.org/10.1080/00224065.1980.11980968

Dong, X., Xu, W., Sikes, R. A., \& Wu, C. (2013). Combination of low dose of genistein and daidzein has synergistic preventive effects on isogenic human prostate cancer cells when compared with individual soy isoflavone. Food Chemistry, 141(3), 1923-1933. https://doi.org/10.1016/j.foodchem.2013.04.109

FAOSTAT. (2020). FAOSTAT. Retrieved from (Accesion Date: 5th January 2022) website: https://www.fao.org/faostat/en/\#home

Filiberto, A. C., Mumford, S. L., Pollack, A. Z., Zhang, C., Yeung, E. H., Perkins, N. J., ... Schisterman, E. F. (2013). Habitual Dietary Isoflavone Intake Is Associated with Decreased C-Reactive Protein Concentrations among Healthy. 900-906. https://doi.org/10.3945/jn.112.173187.among 
González-Montoya, M., Ramón-Gallegos, E., Robles-Ramírez, M. del C., \& Mora-Escobedo, R. (2016). Evaluation of the antioxidant and antiproliferative effects of three peptide fractions of germinated soybeans on breast and cervical cancer cell lines. Plant Foods for Human Nutrition, 71(4), 368-374. https://doi.org/10.1007/s11130-016-0568-z

Gunst, R. F. (1996). Response Surface Methodology: Process and Product Optimization Using Designed Experiments. Technometrics, 38(3), 284-286. https://doi.org/10.1080/00401706.1996.10484509

Haidar, C. N., Coscueta, E., Cordisco, E., Nerli, B. B., \& Malpiedi, L. P. (2018). Aqueous micellar two-phase system as an alternative method to selectively remove soy antinutritional factors. LWT, 93, 665-672. https://doi.org/10.1016/j.lwt.2018.04.025

Hendriks, W. H., Bruininx, E. M. A. M., Gruppen, H., \& Poel, A. F. B. Van Der. (2022). Protein structural changes during processing of vegetable feed ingredients used in swine diets : implications for nutritional value. Nutrition Research Reviews, (2016), 126-141. https://doi.org/10.1017/S0954422416000056

Jackson, B. A., Bahri, P. A., \& Moheimani, N. R. (2017). Repetitive non-destructive milking of hydrocarbons from Botryococcus braunii. Renewable and Sustainable Energy Reviews, 79(May 2016), 1229-1240. https://doi.org/10.1016/j.rser.2017.05.130

Kulling, S. E., Honig, D. M., \& Metzler, M. (2001). Oxidative metabolism of the soy isoflavones daidzein and genistein in humans in vitro and in vivo. Journal of Agricultural and Food Chemistry, 49(6), 3024-3033. https://doi.org/10.1021/jf0012695

Luthria, D. L., Biswas, R., \& Natarajan, S. (2007). Comparison of extraction solvents and techniques used for the assay of isoflavones from soybean. Food Chemistry, 105(1), 325-333. https://doi.org/10.1016/j.foodchem.2006.11.047

Mikelová, R., Zehnálek, J., Vacek, J., Kizek, R., \& Kubá̌, V. (2004). Liquid chromatographic mass spectrometric determination of genistin and daidzin in soybean food samples after accelerated solvent extraction with modified content of extraction cell. Analytica Chimica Acta, 517(1-2), 1-11. https://doi.org/10.1016/j.aca.2004.05.003

Murphy, P. A., Barua, K., \& Hauck, C. C. (2002). Solvent extraction selection in the determination of isoflavones in soy foods. Journal of Chromatography B: Analytical Technologies in the Biomedical and Life Sciences, 777(1-2), 129-138. https://doi.org/10.1016/S15700232(02)00342-2

Oliveira, F. De, Gonçalves, T., Justo, T., Frasão, S., Conte-junior, C. A., Monteiro, M., \& Perrone, D. (2018). Soybean meal and fermented soybean meal as functional ingredients for the production of low-carb, high-protein, high- fi ber and high iso fl avones biscuits. LWT - Food Science and Technology, 90(September 2017), 224-231. https://doi.org/10.1016/j.lwt.2017.12.035

Park, M.-H., Ju, J.-W., Park, M., \& Han, J. (2013). Daidzein inhibits carbohydrate digestive enzymes in vitro and alleviates postprandial hyperglycemia in diabetic mice. European Journal of Pharmacology, 712(1), 48-52. https://doi.org/http://dx.doi.org/10.1016/j.ejphar.2013.04.047

Pyo, D., Yoo, J., \& Surh, J. (2009). Comparison of supercritical fluid extraction and solvent extraction of isoflavones from soybeans. Journal of Liquid Chromatography and Related Technologies, 32(7), 923-932. https://doi.org/10.1080/10826070902787351

Racheva, R., Rahlf, A. F., Wenzel, D., Müller, C., Kerner, M., Luinstra, G. A., \& Smirnova, I. (2018). Aqueous food-grade and cosmetic-grade surfactant systems for the continuous countercurrent cloud point extraction. Separation and Purification Technology, 202(March), 76-85. https://doi.org/10.1016/j.seppur.2018.03.040

Ranjha, M. M. A. N., Irfan, S., Lorenzo, J. M., Shafique, B., Kanwal, R., Pateiro, M., ... Aadil, R. M. (2021). Sonication, a potential technique for extraction of phytoconstituents: A systematic review. Processes, Vol. 9, pp. 1-21. https://doi.org/10.3390/pr9081406

Sadeghalvad, M., Mohammadi-Motlagh, H. R., Karaji, A. G., \& Mostafaie, A. (2019). In vivo anti- 
inflammatory efficacy of the combined Bowman-Birk trypsin inhibitor and genistein isoflavone, two biological compounds from soybean. Journal of Biochemical and Molecular Toxicology, 33(12), e22406. https://doi.org/10.1002/JBT.22406

Seo, S. H., \& Cho, S. J. (2016). Changes in allergenic and antinutritional protein profiles of soybean meal during solid-state fermentation with Bacillus subtilis. LWT - Food Science and Technology, 70, 208-212. https://doi.org/10.1016/j.lwt.2016.02.035

Sharma, S., Kori, S., \& Parmar, A. (2015). Surfactant mediated extraction of total phenolic contents (TPC) and antioxidants from fruits juices. Food Chemistry, 185, 284-288. https://doi.org/10.1016/j.foodchem.2015.03.106

Smith, P. K., Krohn, R. I., Hermanson, G. T., Mallia, A. K., Gartner, F. H., Provenzano, M. D., ... Klenk, D. C. (1985). Measurement of protein using bicinchoninic acid. Analytical Biochemistry, 150(1), 76-85. https://doi.org/10.1016/0003-2697(85)90442-7

Terigar, B. G., Balasubramanian, S., Boldor, D., Xu, Z., Lima, M., \& Sabliov, C. M. (2010). Continuous microwave-assisted isoflavone extraction system: Design and performance evaluation. Bioresource Technology, 101(7), 2466-2471. https://doi.org/10.1016/j.biortech.2009.11.039

V. L. Singleton and J. A. Rossi. (1965). Colorimetry of Total Phenolics with PhosphomolybdicPhosphotungstic Acid Reagents. American Journal of Enology and Viticulture, 16(3), 144158. https://doi.org/10.12691/ijebb-2-1-5

Vicente, F. A., Malpiedi, L. P., Francisca, A., Pessoa, A., Coutinho, J. A. P., \& Ventura, S. P. M. (2014). Design of novel aqueous micellar two-phase systems using ionic liquids as cosurfactants for the selective extraction of ( bio ) molecules. Separation and Purification Technology, 135, 259-267. https://doi.org/10.1016/j.seppur.2014.06.045

$\mathrm{Xu}, \mathrm{H}$. N., \& He, C. H. (2007). Separation and purification of puerarin with solvent extraction. Separation and Purification Technology, 56(3), 397-400. https://doi.org/10.1016/j.seppur.2007.06.003

Yasar, S., Tosun, R., \& Sonmez, Z. (2020). Fungal fermentation inducing improved nutritional qualities associated with altered secondary protein structure of soybean meal determined by FTIR spectroscopy. Measurement, 161, 107895. https://doi.org/10.1016/j.measurement.2020.107895 